\title{
Tuning Collective Cell Migration by Cell-Cell Junction Regulation
}

\author{
Peter FriedI ${ }^{1,2,3}$ and Roberto Mayor ${ }^{4}$ \\ ${ }^{1}$ Department of Cell Biology, Radboud University Medical Centre, Nijmegen 6525GA, The Netherlands \\ ${ }^{2}$ David H. Koch Center for Applied Research of Genitourinary Cancers, The University of Texas \\ MD Anderson Cancer Center, Houston, Texas 77030 \\ ${ }^{3}$ Cancer Genomics Center, 3584 CG Utrecht, The Netherlands \\ ${ }^{4}$ Department of Cell and Developmental Biology, University College London, London WC1E 6BT, \\ United Kingdom \\ Correspondence: peter.friedl@radboudumc.nl; r.mayor@ucl.ac.uk
}

Collective cell migration critically depends on cell-cell interactions coupled to a dynamic actin cytoskeleton. Important cell-cell adhesion receptor systems implicated in controlling collective movements include cadherins, immunoglobulin superfamily members (L1CAM, NCAM, ALCAM), Ephrin/Eph receptors, Slit/Robo, connexins and integrins, and an adaptive array of intracellular adapter and signaling proteins. Depending on molecular composition and signaling context, cell-cell junctions adapt their shape and stability, and this gradual junction plasticity enables different types of collective cell movements such as epithelial sheet and cluster migration, branching morphogenesis and sprouting, collective network migration, as well as coordinated individual-cell migration and streaming. Thereby, plasticity of cell-cell junction composition and turnover defines the type of collective movements in epithelial, mesenchymal, neuronal, and immune cells, and defines migration coordination, anchorage, and cell dissociation. We here review cell-cell adhesion systems and their functions in different types of collective cell migration as key regulators of collective plasticity.

$M$ ulticellular organisms form and maintain their bodies through the ability of individual cells to adhere to neighbor cells by cell-cell junctions, which are mechanically both stable and flexible and secure cell position and function over time. Stable junctions anchor cells in their tissue niche and define cell-cell cooperation and mechanical function such as contraction or cell-cell signaling. These junctions are the basis of all polarized epithelia, vessels, muscle, neuronal tissue, as well as cell organization in connective tissue. Dynamic cell-cell junctions enable cells to change position relative to their neighbors or as multicellular groups; they are relevant during morphogenesis and phases of tissue activation, for example, in response to injury or inflammation (Collins and Nelson 2015). By regulating junction "fluidity," the ag-

Editors: Carien M. Niessen and Alpha S. Yap

Additional Perspectives on Cell-Cell Junctions available at www.cshperspectives.org

Copyright (C) 2017 Cold Spring Harbor Laboratory Press; all rights reserved; doi: 10.1101/cshperspect.a029199

Cite this article as Cold Spring Harb Perspect Biol 2017;9:a029199 
gregate state and dynamics of cells can change remarkably and, accordingly, alter collective functions (Collins and Nelson 2015; Park et al. 2016).

Depending on the cell type and activation state, a range of adhesion receptor and cytoskeletal adaptor systems are involved in securing short- or long-lived, dynamic or stable cellcell interactions. These include cadherins and protocadherins, immunoglobulin (Ig) superfamily members, desmosomal and tight junction (TJ) proteins, as well as integrins, selectins, ephrin/eph receptors, and, likely, connexins, which all directly or indirectly couple to the intracellular cytoskeleton and mediate distinct cell-cell adhesion types (Theveneau and Mayor 2012a; Collins and Nelson 2015). Controlled by upstream signaling, each receptor type can undergo context-dependent alteration in surface expression, ligand interaction, and cytoskeletal coupling, and mediate a range of dedicated types of cell-cell coupling.

Many types of collective cell-cell behaviors depend on stable cell-cell anchorage to form layered cell sheets or complex forms of tissue organization, including barrier function mediated by epithelia and endothelia toward the extra- and intracorporal spaces, intercellular signaling network functions as in neuronal networks, or large-scale contraction and force generation as in muscle or purse-string contraction of epithelia (Tada and Heisenberg 2012; Sunyer et al. 2016). Most dynamic multicellular functions, which depend on long-lived cell-cell junctions lasting hours to days or weeks, can be categorized as collective movements in which clusters, sheets, or strands of cells move as a multicellular unit across or through tissue for developing and maintaining epithelial structures (Friedl and Gilmour 2009; Shamir and Ewald 2015). More dynamic cell-cell junctions lasting in the range of minutes are critical in mediating multicellular crowd behaviors in which groups of cells move individually, but coordinate their directionality and speed by less stable and comparably short-lived adhesions and cell-cell sensing (Theveneau and Mayor 2013). Last, immune cells use even more short-lived cell-cell junctions for coordi- nating their migration and transient clustering with other leukocytes for signal exchange, which depends on very dynamic physical and chemical cell-cell interactions (Malet-Engra et al. 2015).

By combining different adhesion systems in a modular manner in time and space, cells respond to extracellular triggers and tune their levels of cell-cell cooperation. We here summarize the range of cell-cell junction types expressed by different cell types, their morphologies and kinetics, and implications for collective migration, anchorage, and cell dissociation. We further review how different types of cell-cellinteraction-based dynamics and collective cell migration are "tunable" and allow for adaptive strategies of cell movements for different physiological and pathological contexts and discuss their implications for classifying collective and single-cell behaviors.

\section{CELL-CELL ADHESION SYSTEMS}

Common to all adhesion systems is the requirement for an initial interaction between transmembrane cell-surface receptors on adjacent cells, which usually are followed by the recruitment of intracellular adaptor and cytoskeletal proteins. This complex regulates the shape and mechanical stability of the adhesion junction, its interaction with intracellular effectors, and adhesion-mediated activation of downstream signaling pathways. Typically, cells use several complementary adhesion systems in parallel, resulting in a cell-cell interactome (Porterfield and Prescher 2015).

Adherens junctions (AJs). AJs are protein complexes found at cell-cell junctions of epithelial and endothelial tissues that connect the actin cytoskeleton of adjacent cells (Shapiro and Weis 2009). AJs depend on the homophilic binding of calcium-dependent cadherins, which interact via their intracellular domains with several regulatory and cytoskeletal proteins such as p120-, $\alpha-, \beta-, \gamma$-catenin, and vinculin, among others (Harris and Tepass 2010). Although AJs are usually associated with epithelial and endothelial tissues, it has been shown that mesenchy- 
mal cells form transient adhesion complexes in which type I N-cadherin, together with the full repertoire of intracellular adhesion proteins ( $\mathrm{p} 120, \alpha-, \beta-, \gamma$-catenin, and vinculin), are engaged (Theveneau and Mayor 2012a). Both Eand N-cadherin-based AJs control apicobasal, as well as front-rear, polarity of interacting cells (Venhuizen and Zegers 2016).

The main functional difference between epithelial and mesenchymal AJs is their stability: epithelial junctions tend to be more stable (in the range of hours to days), whereas mesenchymal junctions are transient (minutes to hours) (Scarpa et al. 2015). The stability of AJs is controlled by several mechanisms, including endocytosis and cytoskeletal regulation. Endocytosis of AJ receptors and adapters occurs both by clathrin-dependent and -independent mechanisms (Delva and Kowalczyk 2009; Schill and Anderson 2009), which cooperate with regulation by Rho family GTPases. For example, Cdc42 works upstream of Par6/aPKC and Cdc42-interacting protein 4 (CIP4), which control actin dynamics at the internalization site (Harris and Tepass 2010). Besides controlling the stability of cell-cell interactions, Rho GTPases, via PAK and $\beta$ PIX, are reciprocally controlled by AJs in which they play an essential role on actin dynamics (Zegers et al. 2003; Zegers and Friedl 2014). Interaction between cadherin-catenin clusters leads to the recruitment of the Rac guanine nucleotide exchange factor (GEF) TIAM1, which activates the Rho GTPase Rac1, and the activation of Rac1 in leader cells is, in turn, required for the formation of cell protrusions and traction forces observed at the edge of a cell cluster during collective cell migration (Hordijk et al. 1997; Kovacs et al. 2002; Mertens et al. 2005). Another activator of Rho GTPases within the AJ is Nectin, and Nectin-like proteins, a family of Ig-like cell adhesion molecules (CAMs) (Takai et al. 2008). To aid the formation of AJ, nectin recruits afadin and ponsin, which lead to the activation of Cdc42 and Rac and cytoskeletal remodeling at the site of cell-cell contact (Fukuyama et al. 2006). The interaction between AJs and actin is mutual, leading to an increase in the stability of cortical actin toward the maturing AJ com- plex (Baum and Georgiou 2011). Consequently, AJ are central hubs controlling cell-cell cohesion and collective cell migration underlying tissue dynamics and remodeling.

Tight junctions (TJS). TJs are adhesion complexes in which the plasma membranes of adjacent cells become closely associated, forming an impermeable barrier within the tissue. TJs are indispensable for creating a barrier between different regions of the body, and their main role is to function as paracellular gates that restrict diffusion on the basis of size and charge. TJs are composed of transmembrane proteins (claudin, occludin, tricellulin, and marveld3) that seem sufficient to trigger at least some of the aspects required in $\mathrm{TJ}$ formation, including mechanical junction stability and apicobasal polarity of connected cells (Zihni et al. 2016). Other TJ transmembrane adhesion proteins comprise the junctional adhesion molecules (JAMs), which enhance TJ stability and turnover (Ebnet et al. 2004; Luissint et al. 2014). The intracellular function of TJs depends on a dense network of proteins, composed of ZO1, ZO2, ZO3, plus a large number of other adaptor proteins (Van Itallie and Anderson 2014). By binding several transmembrane and adaptor proteins, TJs control various signaling pathways involved in actin organization, cell polarity, as well as transcriptional regulation (Gonzalez-Mariscal et al. 2014). The interaction of TJ proteins with the actin cytoskeleton seems to be essential for junction formation and turnover. For example, myosin light chain kinase stimulates TJ remodeling and occludin internalization during inflammation (Herrmann and Turner 2016). Rho GTPase signaling is also controlled by TJassociated proteins: RhoA, Cdc42, and Rac are regulated by GEFs recruited to cingulin, ZO1, and tricellulin (Otani et al. 2006; Terry et al. 2011; Oda et al. 2014). Thereby, TJs form a central hub between cell-cell interactions and actin dynamics (Balda and Matter 2016).

Gap junctions (GJs). GJs are intercellular membrane channels made up of a multigene family, called connexins in vertebrates (Willecke et al. 2002). GJs are specialized junctions char- 
acterized by close apposition of the plasma membranes between neighboring cells and contain a hydrophilic channel that mediates the intercellular passage of molecules $>1 \mathrm{kDa}$ in size. The extracellular domains of connexins form a tight connection between adjacent cells contributing to cell-cell adhesion. Connexins interact with several proteins to form multiprotein complexes, which are important in cell-cell junction stability and function. For example, Cx43 interacts with $\mathrm{N}$-cadherin and other members of the AJ complex (Xu et al. 2001), as well as cytoskeletal proteins such as microfilaments and microtubules (Wei et al. 2004). Phosphorylation of the cytoplasmic domain of connexin is critical in regulating GJ assembly, trafficking, channel gating, and turnover. GJs contribute to cell migration during development and in homeostatic processes such as wound healing (Kotini and Mayor 2015), and it has been proposed that their channel activity could be important for cell coupling and coordination during migration (Lorraine et al. 2015).

IgCAMs. IgCAMs correspond to immunoglobulin-like cell-adhesion molecules containing one or more Ig-like domains in their extracellular regions. IgCAMs are expressed in a wide variety of cell types, such as cells of the nervous system, leukocytes, and epithelial and endothelial cells (Cavallaro and Christofori 2004). By homophilic and heterophilic interactions of their Ig-like domains IgCAMs mediate adaptive cell-cell interactions and play an important role in cell migration (Cavallaro and Christofori 2004). IgCAM adhesion is regulated by lateral oligomerization, which in turn depends on phosphorylation of their Ankyrin-binding domain (Garver et al. 1997). A second mechanism that controls IgCAMs-mediated adhesion is based on their internalization or recycling from the plasma membrane; for example, the internalization of aplysia cell adhesion molecule (apCAM) is controlled by phosphorylation by mitogen-associated protein (MAP) kinase (Bailey et al. 1997). A third mechanism that regulates IgCAM-based cell adhesion is their proteolytic cleavage. For example, the leukocyte adhesion molecule L-selectin is cleaved by sheddases of the metalloprotease and ADAM families, and is protected from this cleavage by intracellular regulators, which engage with its cytoplasmic domain, including calmodulin and moesin (Kahn et al. 1998; Ivetic et al. 2002). IgCAMs have been reported to associate with a range of other proteins at the cell membrane, including growth-factor receptors, integrins, and cadherins, and with intracellular proteins, such as effectors of signal transduction pathways and cytoskeletal proteins (Juliano 2002), and thus contribute to a range of signaling programs involved in cell adhesion and migration.

Slit/Robo. Slit/Robo corresponds to the Roundabout receptors (Robo) and their Slit ligand. Robo receptors belong to the superfamily of IgCAMs and engage in both homophilic and heterophilic interactions (Hivert et al. 2002). Slits are the principal ligands for the Robo receptors (Kidd et al. 1999), which, together with heparan sulphates, form a ternary complex required for signaling (Ypsilanti et al. 2010). The cytoplasmic domains of Robo do not possess catalytic activities and, therefore, interact with different signaling molecules to exert their specific effects; these include netrin and several GTPase activating proteins (GAPs) and GEFs that control actin cytoskeletal dynamics by regulating the activity of RhoA, Rac1, and Cdc42 (Ypsilanti et al. 2010). The activity of Slit/Robo, including adhesion, is controlled by transcriptional regulation and endocytosis and degradation (Keleman et al. 2005). Slit-Robo interaction typically mediates cell repulsion, but in some cases also supports cell-cell adhesion. The formation of cranial ganglia requires the adhesion to different cell types, and increased adhesion between neural crest and placodes is promoted by an interaction between Robo2/ Slit1, which increases the N-cadherin-dependent adhesion between these cells (Shiau and Bronner-Fraser 2009). Slit/Robo interactions are also involved in collective cell migration of neural crest cells during development and endothelial cells in angiogenesis (Legg et al. 2008). 
Ephrin/Eph receptor. Ephrin/Eph receptor corresponds to a pair of ligands and receptors involved in short-distance cell-cell signaling. Eph are Tyr kinase receptors and ephrins are membrane-tethered ligands, which can elicit signaling that affects the cytoskeleton, mediating primarily cell repulsion but, depending on context, also cell-cell adhesion (Kania and Klein 2016). Phosphorylation of the intracellular domains of Ephs regulates the recruitment of effector proteins, such as the noncatalytic regions of Tyr kinase adaptor protein 1 (Nck1) and Nck2, Vav2 and Vav3, Src, $\alpha 2$-chimerin, and ephexins, which directly regulate actin or modulate the activity of the small GTPases RhoA and Racl (Kania and Klein 2016). Normal morphogenesis of the neural tube and neural progenitors requires ephrin-dependent cellcell adhesion (Arvanitis et al. 2013), and alternative usage of different splice forms of Eph receptor was implicated in mediating cell-cell coupling during embryonic development. Eph signaling promotes the formation of $\mathrm{AJ}$ through interaction with E-cadherin and TJs via the interaction with claudin (Dravis and Henkemeyer 2011). Likely, the consequences of Ephrin/Eph interactions for cell-cell contact stability depend on the overall junction protein repertoire expressed by the cell. Ephrin/Eph has been shown to be important for collective movement; for example, the formation of the thymus anlage requires $\mathrm{EphB} /$ ephrin $\mathrm{B}$, which seems to support collective mobility by a collective separation mechanism (Foster et al. 2010).

Integrins. Integrins are transmembrane proteins that connect the cytoskeleton with the extracellular matrix (ECM). ECM ligands for integrins include fibronectin, vitronectin, collagen, and laminin, among others, which, beyond their well-established function as structural connective tissue scaffolds, also may be located between cells and contribute to cell-cell interactions (Barczyk et al. 2010). Integrins interact with F-actin and intermediate filaments allowing a mechanical coupling between the cytoskeleton and the ECM, and act as important transducers of mechanical forces (Fagerholm et al. 2005). Integrin en- gagement results in the formation of focal adhesion complexes of varying sizes and functions, which interact with F-actin and recruit FAK and Src, leading to the activation of signaling pathways involving extracellular signalregulated kinase (ERK), c-Jun N-terminal kinase (JNK), and small GTPases (Bouvard et al. 2013). Interaction of integrins with cadherins and selectins has been proposed to be required for the participation of integrins in cell-cell adhesion (Bouvard et al. 2013).

\section{CELL-CELL ADHESION STATES AND DYNAMICS}

The type and durability of cell-cell adhesion and cytoskeletal interaction systems that are engaged by stationary and moving cells provide a range of adhesion strategies between cells, which jointly define the level of collective adhesion and polarity, junction dynamics, and the type of collective migration. The spectrum of tissue fluidity can be found to vary, in a celland context-dependent manner, from fully immobilized, highly contractile to loosely connected but highly mobile collective cell-cell organizations and kinetics (Fig. 1).

Myoblast fusion and myofiber formation. Myofibers are multicellular syncytia that develop by the fusion of individual myoblasts. Rather than forming a collectively migrating group, myoblasts remain stably anchored to the substrate while establishing stable cell-cell junctions that enable contractility across many cells but show little junction dynamics. Myoblast interactions engage multiple receptor systems in parallel, including focalized highdensity accumulation of $\mathrm{M}$ - and $\mathrm{N}$-cadherin, neural cell adhesion molecule (NCAM), vascular cell adhesion molecule (VCAM-1), meltrin, and integrins (Fig. 1A) (Charrasse et al. 2006; Abmayr and Pavlath 2012; Ozawa 2015). Once myoblasts connect with each other, individual mobility is largely disabled, whereas collective contractility and force transmission across cell-cell junctions are gained, particularly through the actomyosin cytoskeleton, which develops prominent stress fibers under the 
P. Friedl and R. Mayor

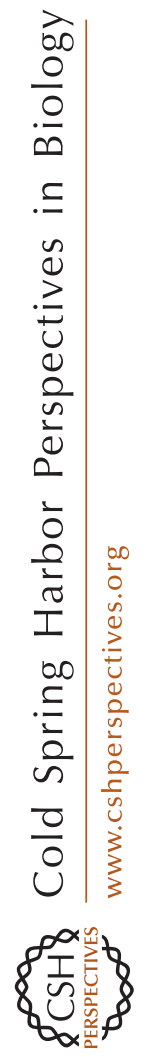

แ
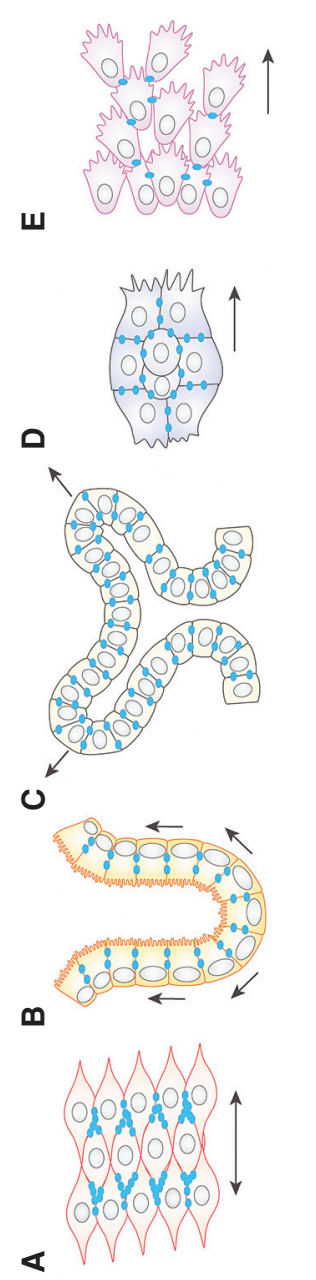
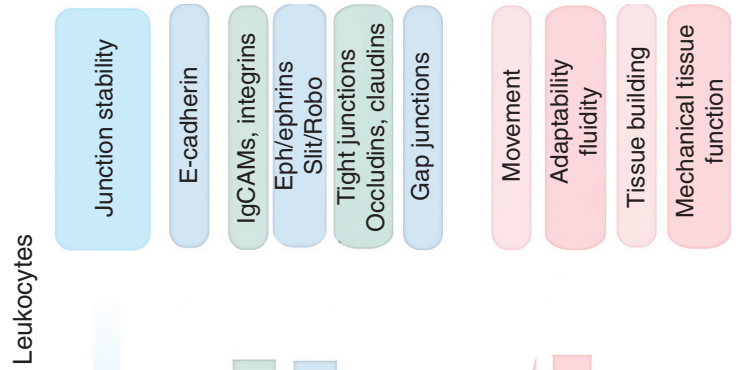

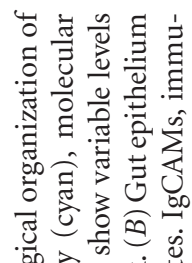

:

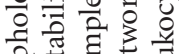

웡

\%

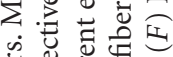

范

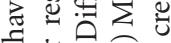

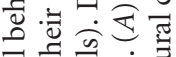

$\bar{\Xi} \dot{\vec{\Xi}}$

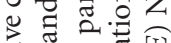

㣢四

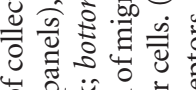

पू

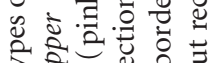

स्ञ

पु

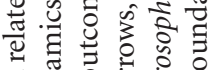

클

त्व

至

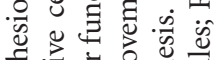

\& 3 \&

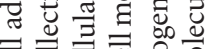

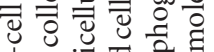

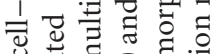

उ ह क

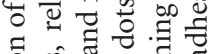

.0

:

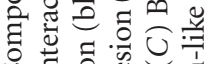

U..

ข

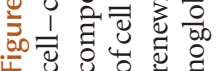
$\frac{10}{0}$
$\frac{N}{2}$
$\sum$ 
control of RhoA and bridges multiple cell bodies for coordinated rhythmic contractility of the multicellular ensemble (Charrasse et al. 2006). Thus, in fusing myoblasts high junction stability mediated through overlapping adhesion systems and cytoskeletal linkages support mechanically very stable junctions, which mediate collective contractility and eventually cell fusion, but discourage position change of the group as a whole and individual cells within the group.

Epithelial sheet migration. Mature monolayered epithelia display stable cell-cell interactions, established by E-cadherin- and $\beta$-catenin-based AJs, combined with apical desmosomal junctions and TJs; these jointly mediate mechanically robust multicellular integrity, apicobasal polarity, and barrier function (Wong et al. 1998; Takeichi 2014). Whereas the epithelium as tissue remains anatomically stable to sustain live-long mechanical and functional integrity, epithelial renewal in several tissues, including the intestine and the epidermis, depends on constitutive collective sheet migration coupled to cell proliferation and sheet expansion (Wong et al. 1998; Nanba et al. 2015). The renewal of the gut epithelium is initiated by releasing precursor cells from the stem cell pool, which resides at the bases of the crypts, and that then change position and move upward along the basement membrane toward the tips of the villi (Ritsma et al. 2014). Because moving cells remain fully coupled to their neighbors by lateral junctions and the intestinal basement membrane via their basal plane, they move as cohesive sheets in the upward direction (Fig. 1B) and, additionally, undergo a controlled number of cell divisions (Wong et al. 1998; Nanba et al. 2015). The mechanics of lateral sheet migration is not fully resolved. Likely, cryptic lamellipodia generate traction force toward the substrate along the sheet, whereas the apical cell-cell junctions transmit collective actomyosin contractility to enable slow movement along the basement membrane (Farooqui and Fenteany 2005; Zegers and Friedl 2014; Bazellieres et al. 2015), but the role of additional rotational and turbulent movements remains to be clarified (Nanba et al. 2015). By coupling apicobasal polarity with high junction stability, sheet migration along a two-dimensional (2D) substrate layer as guidance cue is a conserved and important type of collective migration of a mature epithelium. Accelerated variants of epithelial sheet migration are observed as sheet migration during the wound closure of epithelial defects and epithelial morphogenesis.

Sprouting strands. When invading 3D tissues, epithelial and endothelial cells typically move collectively to form linear, branched, or network-like strands (Fig. 1C). Collective sprouting underlies the branching morphogenesis of epithelial tissue and organs with branched or lobular structure, including the trachea, kidney, thymus, and the mammary gland (Gray et al. 2010). Sprouting hemo- or lymphangiogenesis occurs during revascularization of tissue after injury (Senger and Davis 2011). As a biomechanical principle of sprouting in differentiated endothelia and epithelia, one or several leader cells form a leading tip or terminal end bud that protrudes forward, whereas the rear cells undergo apicobasal polarization to form a vascular lumen or duct (Huebner et al. 2016). The cell-cell junctions of invading epithelial strands are dependent on Ecadherin-based AJs, desomosomal, and TJs (Shamir and Ewald 2015), whereas vascular strands depend on VE-cadherin and TJs (Senger and Davis 2011). Commonly, these cell strands preserve apicobasal polarity, form lumina, and deposit an abluminal basement membrane as they move, as has been observed during vascular, mammary gland, kidney, and tracheal development (Riggins et al. 2010; NguyenNgoc et al. 2012). When apicobasal polarity is lacking, as in dedifferentiated tumor cells, collective strand invasion occurs as solid finger-like multicellular protrusions with no lumen formed (Wolf et al. 2007; Nguyen-Ngoc et al. 2012).

Moving sheets and clusters. In morphogenesis and during cancer invasion, cell sheets and 
detached groups of variable size, which retain cohesive cell-cell junctions between cells, migrate along $2 \mathrm{D}$ and three-dimensional (3D) tissue scaffolds (Fig. 1D) (Friedl et al. 1995; Alexander et al. 2008; Montell et al. 2012). Epithelial sheet movement is initiated by a row of leader cells coupled to follower cells by AJs containing E- or P-cadherin (Chapnick and Liu 2014; Plutoni et al. 2016), and sheet displacement depends on coordinated traction force generation between leader and follower cells, which are distributed across cell-cell junctions by the actomyosin cytoskeleton (Brugues et al. 2014; Reffay et al. 2014; Bazellieres et al. 2015). Moving clusters can be epithelial, such as the border cells moving along the boundaries of large nurse cells of the developing Drosphila ovary, or mesenchymal, such as moving neoplastic sheets in rhabodomyosarcoma explant culture (Friedl et al. 1995). The activity of leader cells depends on extracellular stimuli, such as ECM ligand or soluble factors (e.g., transforming growth factor $\beta$, TGF- $\beta$ ), inducing MAP kinase signaling and downstream Racl for protrusion formation and direction sensing (Khalil and Friedl 2010; Chapnick and Liu 2014). Leader cell polarity is further supported by AJ signaling, which controls leader cell polarization and anterior protrusion dynamics (Khalil and Friedl 2010; Mayor and Etienne-Manneville 2016). In contrast to homeostatic sheet migration, which forms a continuum without leading and trailing edges, the mechanisms defining retraction of the rear cells in moving clusters remain unclear.

Moving cell networks. A more flexible type of collective migration, used by neural crest and other mesenchymal cells, as they move in a coordinated manner as loosely cohesive group in a cell-type and context-dependent way, with a variable tendency to individualize (Fig. 1E) (Scarpa et al. 2015). Examples are the migration of neural crest cells in developing embryos, neuronal/astrocyte networks (Scarpa et al. 2015), glioma cells retaining filamentous cell-cell interactions while moving through complex brain parenchyma (Osswald et al. 2015), and mesenchymal tumor cells moving through confining tissue (Ilina et al. 2011; Haeger et al. 2014). Collectively, moving loose networks are mediated by complex morphological junctions mediated by N-cadherin for cell-cell adhesion and additional receptors mediating repulsive signals, including Ephrin/Eph receptors (Theveneau and Mayor 2011). As a consequence, cells coordinate their polarity and respond to extracellular signals as a group, but also retain the remarkable ability of moving individually. Mesenchymal tumor cells develop ALCAM-positive cell-cell junctions when moving through confined space, and gain many properties of collective invasion, including shared migration path, lateral cell-cell junctions, and alignment of front-rear polarity and mitotic planes (Haeger et al. 2014). But they also retain the ability to rapidly detach in response to extracellular signals such as growth factors, altered tissue geometry, or matrix metalloproteinase (MMP) availability (Wolf et al. 2007; Ilina et al. 2011). Conceptually, collective networks retain properties of both collective and individual cell movements, as well as multicellular streaming, and further show a high level of stochasticity ("noise") in switching between individual and collective behaviors, which render experimental classification sometimes challenging and requires quantitative analysis as well as mathematical modeling (Huang et al. 2015). As a defining characteristic for collective cooperativity, the cells moving as a network can respond more efficiently to external signals when they are part of groups rather than as individual cells (Theveneau et al. 2010).

Leukocyte swarming and aggregation. When activated, moving leukocytes show a strong tendency to interact with each other, coordinate their migration for "swarming" behaviors, and aggregate. In activated lymphoblasts, $\alpha \mathrm{L} \beta 2$ integrin/ICAM-1-dependent cell-cell junctions transiently interact and coordinate their migration as cell pairs or small clusters of variable stability (Gunzer et al. 2004; Malet-Engra et al. 2015). As moving myeloid leukocytes converging toward damaged or infected tissue regions, chemoattractant guidance leads to highly coordinated crowd behaviors with head-to-tail ori- 
entation and frequent cell-cell interactions, which can eventually transit to firm clustering that depends on $\beta 2$ integrin availability (Waite et al. 2011; Lammermann et al. 2013). Thus, at the low end of cell-cell adhesion, individually moving leukocytes may coordinate their amoeboid movements with neighboring cells by short-lived cell-cell junctions (seconds to minutes), and rapidly transit toward contact strengthening and aggregation into a multicellular cluster. Depending on experimental context, such clusters may be immobile and transiently close an interstitial wound (Lammermann et al. 2013) or, under chemotactic and free-space conditions, even show collective coordination and migration (Malet-Engra et al. 2015).

In summary, for very different cell types and biological contexts, the organization and stability of cell-cell junctions, together with environmental parameters, determines the morphological and functional types of collective movement. Consequently, alteration of adhesion and environmental parameters may impose an adaptation response and significant plasticity of collective behaviors.

\section{TUNING COLLECTIVE MIGRATION: VARIABILITY AND TRANSITIONS}

The molecular variability of cell-cell junctions and their different linkages to the cytoskeleton not only explain distinct types of collective movements; when regulated within the same cell type, by extracellular chemical or physical signals, collective migration may be induced or modulated, with consequences for group behavior and tissue integrity and function.

\section{Tissue Morphogenesis and Regeneration}

Morphogenesis involves the complex and coordinated rearrangement of tissues and massive movement of cells. In particular, the initial formation of the body shape, the early separation of the principal tissue types, and the organization of specific organs depend on different types of collective cell migration. Similar morphogenetic processes are implicated in regeneration.
A fundamental morphogenetic process that allows tissues to develop and remodel and that depends on the regulation of cell-cell adhesions is the epithelial-to-mesenchymal transition (EMT). In response to extracellular triggers, including cytokines, growth factors, and metabolic stress, EMT induces the down-regulation of E-cadherin but up-regulates N-cadherin, which lowers cell-cell adhesion strength and apical-basal cell polarity, and favors migratory and invasive properties (Thiery et al. 2009). Traditionally, full EMT has been considered essential for the migration as it was thought that only mesenchymal, but not epithelial cells, were able to migrate. However, recent work indicates that EMT should be considered as a spectrum of intermediary phases, ranging from full EMT to partial, or even quite subtle states of EMT with very variable effects on cell mobility and migration type (Fig. 2) (Nieto et al. 2016). Well-studied examples of collective cell migration during development, which are initiated by or maintain some degree of EMT, include the migration of border cells in Drosophila, the lateral line primordium in zebrafish, and the neural crest in amphibian and zebrafish (Mayor and EtienneManneville 2016). The precursors of all these tissues are epithelial cells that undergo an EMT to initiate their migration; the degree and pattern of collective cooperation during migration thereafter reflects varying cell-cell junction organization and dynamics maintained by varying coexistence of epithelial and mesenchymal programs (Fig. 2). The zebrafish lateral line primordium represents collective cell migration, which retains both epithelial and mesenchymal characteristics as a default state (Fig. 2A,B) (Ghysen and Dambly-Chaudiere 2004). Cells of the primordium express E-cadherin and show foci of the TJ protein $\mathrm{ZO} 1$ and aPKC at the center of the tightly packaged primordium (Revenu et al. 2014), similar to mature epithelium. On the other hand, cells particularly located at the edge of this cell group display typical mesenchymal characteristics, such as reduced apicobasal polarity and the presence of highly dynamic actin-rich lamellipodia-like protrusions at the basal interactions to the tissue (Lecaudey et al. 2008; Hava et al. 
P. Friedl and R. Mayor

A
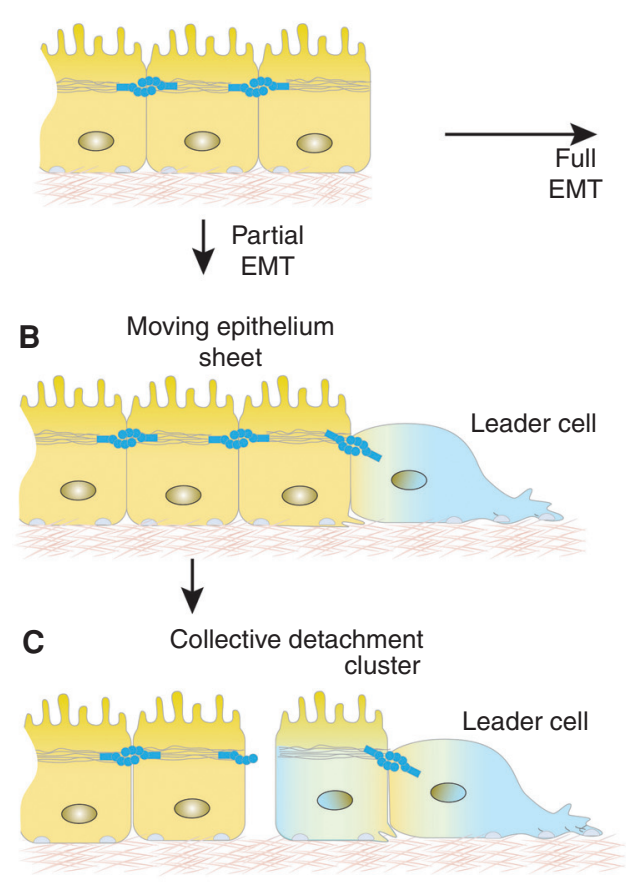

D
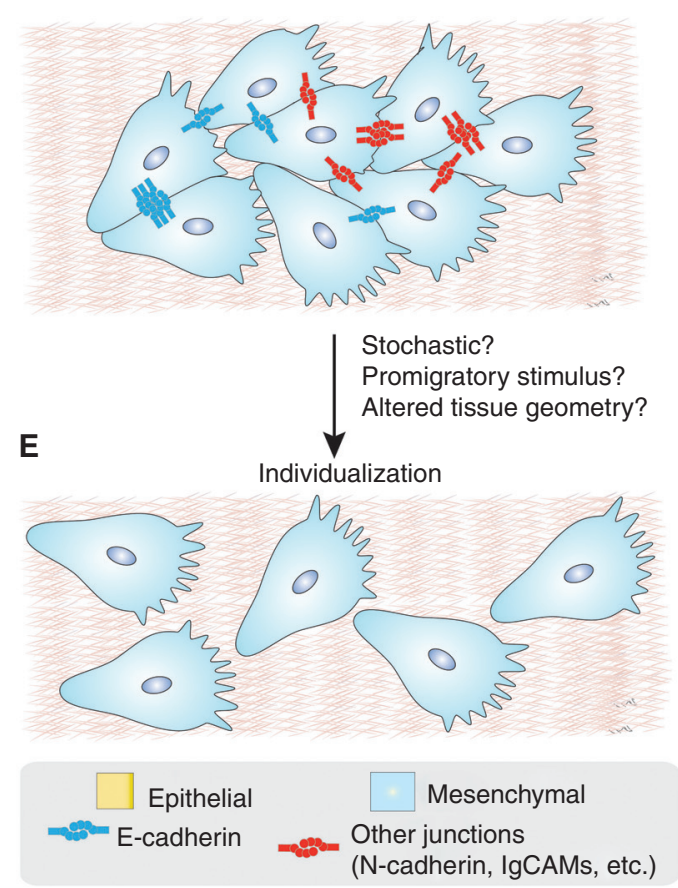

Figure 2. EMT spectrum tuning the modes of collective and individual-cell migration. $(A)$ Resting epithelial tissue. (B) Partial EMT in the leading cells can retain cell-cell junctions and promote epithelial sheet migration. $(C)$ Cluster migration after group detachment from the main tissue. Migrating clusters can maintain apicobasal polarity, strong and stable cell adhesion mediated mainly by E-cadherin, or undergo further mesenchymal plasticity. $(D, E)$ Full EMT leads to reduced cell adhesion, associated with down-modulated E-cadherin and increased $\mathrm{N}$-cadherin expression, followed by loss of apicobasal polarity, acquisition of front-back polarity and increased individual motility. Transient junctions allow for collective network migration $(D)$, and complete resolution of cell-cell junctions favors individualization and single-cell migration (E). EMT, epithelial-tomesenchymal transition; IgCAMs, immunoglobulin-like cell-adhesion molecules.

2009). Thus, within the same moving cell group, different interaction types are found, with strong cell-cell adhesions at the center of the migrating cluster and more mesenchymal cells with weaker adhesions but higher actinmediated mobility at the periphery and in leader cells.

Branching morphogenesis in the lactating mammary gland and cell movements during gut homeostasis are also seemingly equivalent to the initial branching morphogenesis observed during development, as both processes require E-cadherin-mediated cell-cell cohesion for collective sprouting and tubule elongation; depletion of E-cadherin interferes with the in- tegrity of these tissues, with E-cadherin deficient cells being excluded (Shamir and Ewald 2015). The leading front of the tube, which drives collective mobility, undergoes a loosening (but not ablation) of cell junction stability, for example, by maintaining a partial EMT in which E-cadherin-based junctions gain flexibility and increase their turnover; concurrently cells in the rear position, which form the extending tube, retain stable cell-cell junctions and apicobasal polarity, and gradually downscale their migration ability (Shamir and Ewald 2015). Likely, similar reprogramming of leader cells toward loosened junction organization is active during neoplastic invasion of 
breast cancer cells (Cheung et al. 2013; Cheung and Ewald 2014). Thus, tuning cell-cell junction stability regulates the degree of collective dynamics.

As an example of a very transient EMT followed by epithelial collective migration, Drosophila border cells initiate their delamination from the epithelium by down-regulation of DEcadherin for a short time period (few hours) (Fig. 2C) (Montell et al. 2012). A network of transcription factors, including Jing, SIX4, Yan, Similar (also known as HIF1 $\alpha$ ), Hindsight (HNT), and Jun-related antigen, is activated and controls the levels of DE-cadherin during border cell delamination and migration (Montell et al. 2012). Levels of DE-cadherin need to be precisely regulated and deviations impair border cell migration; consequently, after initially reducing DE-cadherin levels during delamination, moving border cell clusters still maintain substantial levels of both DE-cadherin and its binding partner armadillo ( $\beta$-catenin) between neighboring border cells to maintain collective migration as a cluster (Peifer 1993; Niewiadomska et al. 1999; Sarpal et al. 2012).

As an example for even stronger mesenchymal properties with few epithelial features retained, in many species the neural crest undergoes EMT to initiate migration (Thiery et al. 2009; Theveneau and Mayor 2012b). In addition, after delamination a collective networktype migration is retained whereby loosely connected individually moving cells and more tightly connected clustered cells both depend on cell-cell interactions for their migration (Fig. 2D) (Teddy and Kulesa 2004; CarmonaFontaine et al. 2008). A complex genetic network is activated in the neural crest that leads to and maintains EMT. A BMP4-Wnt1 signaling pathway activates a set of transcription factors, including Snail1/2, Sox $5 / 9 / 10$, Foxd 3 and Ets1, that modify the expression of cell-cell and cell-matrix adhesion molecules (Sauka-Spengler and Bronner-Fraser 2008; Theveneau and Mayor 2012c). Thus, although neural crest shows all the hallmarks of mesenchymal cells, they obviously form transient AJs (Scarpa et al. 2015). The endocytosis of N-cadherin at the AJs is essential for neural crest migration in vivo, as it confers sufficient fluidity on the cell cluster for it to migrate under physical constrains (Kuriyama et al. 2014). This increase in tissue fluidity allows a dynamic exchange of neighbors while retaining cell-cell interaction.

In conclusion, collective cell migration during morphogenesis involves a wide spectrum of cell adhesion strength, with highly cohesive cell sheets and clusters at one end and relatively loose groups of cells at the other end. By spatially and temporally tuning cell-cell junction stability, a range of collective migration modes and patterns with different levels of cell-cell cohesiveness is achieved to build tissue.

\section{Cancer Invasion and Metastasis}

Collective invasion is an important strategy for local tissue infiltration, as well as metastatic evasion in epithelial tumors such as breast cancer, squamous cell carcinoma, colon cancer, and others, as well as in mesenchymal tumors (Ilina and Friedl 2009; Cheung and Ewald 2016). Similar to morphogenesis, the phenotypic and junctional organization of moving cancer cell groups varies greatly ("collective plasticity"). In experimental live-cell models, all types of collective movements can be adopted by tumor cells including (1) cohesive sheets or strands, typically detected in epithelial cancers; (2) isolated clusters detached from the primary/metastatic lesion such as epithelial tumors and melanoma; (3) neuronal-like networks of connected cells, detected in neuroectodermal tumors, such as glioblastoma; or (4) as "jammed" collective cohorts induced by spatially narrow tissue boundaries (confinement) of otherwise transiently/loosely connected (single) cells in experimental melanoma and sarcoma models (Friedl et al. 1995, 2012; Nguyen-Ngoc and Ewald 2013). Similarly, histological examination of both patient lesions and mouse models in vivo shows that the collective invasion patterns develop striking morphological and molecular variability, depending on tumor type and the tissue that is invaded (Weigelin et al. 2012; Bronsert et al. 2014).

Consistent with cellular diversity of collective invasion programs, a range of cell-cell 
adhesion mechanisms supports collective invasion of cancer cells. Epithelial tumors invade collectively, with duct-like patterns and E-cadherin and $\beta$-catenin positive cell-cell junctions, with or without lumen formation, and with or without up-regulation of EMT markers, including Twist and Zeb1 (Cheung et al. 2013; Bronsert et al. 2014). Furthermore, both E- and $\mathrm{N}$-cadherin can orchestrate AJs and cell-cell interactions in cancer cells (Bronsert et al. 2014; Zucchini et al. 2014). Besides cadherins, Ig superfamily members and ephrins/EpH receptor systems were implicated in mediating more labile or transient cell-cell interactions in cancer cells (Cavallaro and Christofori 2004; Haeger et al. 2014; Krusche et al. 2016). As well, connexins may enable communication through GJs between connected tumor cells and their inhibition reduces collective migration in prostate cancer cells (Zhang et al. 2015). Similar to morphogenetic and homeostatic migration, collectives of migrating cancer cells display leader cells that engage with surrounding tissue structures via Rac-driven filopodal protrusions and integrin-mediated substrate adhesion ( $\mathrm{He}-$ gerfeldt et al. 2002; Yamaguchi et al. 2015). Collectively moving cancer cells retain a range of actin dynamics, substrate adhesions, and ECM remodeling functions, which typically are shared and coordinated between neighboring cells, generate tissue alignment and remodeling as an integrated process; these combined parameters can further define the degree of cellcell cohesion and individualization as an integrated function of cell-cell junction stability, MMP activity and tissue organization, and space (Scott et al. 2010; Friedl et al. 2012; Te Boekhorst et al. 2016).

In recapitulation of morphogenesis programs, EMT signaling enhances cancer invasion and metastatic progression of epithelial cancers by reprogramming cell-cell junctions (Kalluri and Weinberg 2009). EMT weakens or fully dissolves cell-cell junctions between cancer cells, including AJs, desmosomes, and TJs. EMT also up-regulates the expression of stromal proteases, which cleave cadherins; deregulates integrin adhesion systems, for example, by switching $\beta 1$ to $\beta 3$ integrin expression and enhancing $\alpha \mathrm{V}$ integrin signaling; and can redirect Rho-mediated actomyosin contractility from cell-cell junctions toward cell-matrix interactions (Kalluri and Weinberg 2009; Parvani et al. 2013; Truong et al. 2014). These molecular reprogramming events result in deregulated cellcell contacts, loss of apicobasal polarity, including degeneration of the lumen of otherwise ductal and glandular structures, gain of frontrear polarity, and ultimately favor the gradual transition from epithelial to mesenchymal migration modes (Bryant et al. 2014).

In addition to tumor cell individualization caused by full EMT, which allows for single-cell dissemination and metastasis, recent cell-based and modeling work indicates that EMT also contributes to collective invasion with a high likelihood of mixed behaviors after EMT, including intermediate (e.g., metastable or hybrid) phenotypes such as detached collective or loosely connected migrating groups (Jolly et al. 2015). With such EMT-associated reprogramming, or partial EMT, moving tumor cell clusters may still maintain cell-cell contacts but simultaneously undergo a differentiation switch toward embryonic features (Jolly et al. 2015; Nieto et al. 2016). Thus, similar to morphogenesis, the adaptability of collective invasion programs allows a range of coping strategies for cancer invasion and metastasis in different tissue environments (discussed in $\mathrm{Te}$ Boekhorst and Friedl 2016).

\section{CONCLUDING REMARKS}

Cell-cell junctions emerge as central regulators of the type, efficiency, and fate of collective cell movements. Here, we have proposed an integrative view to frame collective cell functions that is distinguished by modular and often gradual cell-cell adhesion regulation. We hope that this perspective may facilitate the understanding of multicellular dynamics with mixed phenotypes, which are frequently observed in wet-laboratory experiments and also in mathematical modeling (Jolly et al. 2015; Te Boekhorst et al. 2016). By modulating the composition of cellcell adhesions, collective movements are adaptive in time and space in response to soluble and 
structural tissue-derived signals, as well as geometric tissue properties (Haeger et al. 2015; Te Boekhorst et al. 2016). Thus, similar to singlecell migration modes, which can switch between different types of mesenchymal and amoeboid movements, collective migration modes can interconvert and adapt to local and global signals.

Based on their range of stability, cell-cell junctions may be classified as (1) stable, cohesive with disabled cell position change, (2) stable, but dynamic, allowing cells to move relative to neighbors without resolving the junction, (3) partially stable, allowing transient detachment and reintegration, and (4) short lived and partially repulsive. Emergent collective behaviors, that is, the ability of a cell group to perform tasks beyond the abilities of a single cell, are reached as long as cell-cell junctions suffice to coordinate behavior across scale. Examples are collective chemotaxis and durotaxis, which allow cell groups to respond to more shallow chemical or physical gradients for directional migration (Malet-Engra et al. 2015; Sunyer et al. 2016). The gradual range of kinetic states complicates simple classifications as "collective" movement versus multicellular streaming versus predominantly single-cell dynamics. Typical collective cell migration is considered when stable cell-cell junctions support supracellular coordination of cytoskeletal activity across multiple cell bodies and even passive cell transport as part of group behaviors (Friedl et al. 2012). Likewise, emergent collective behaviors can also be observed when cell-cell junctions are transient junctions, particularly in chemotactic gradient sensing and signal integration. Thus, multicellular streaming behavior depends on the active movement of every cell but still retains multiple reciprocal cellcell interactions, which are limited in duration and stability but enable collective gradient sensing (Theveneau et al. 2010; Ellison et al. 2016). Last, individually moving cells may still engage with other cells in short-lived junctions, which may or may not induce repulsion and directional change, and thereby retain cooperative input from neighboring cells (Ellison et al. 2016). As a special case, an otherwise loosely connected cell may upscale cooperativity as part of, for example, a cell-jamming transition when cells are confined in tissue space, and thereby adopt emergent behaviors, including persistent intercellular adhesion and signal integration (Haeger et al. 2014; Sarkar et al. 2016). Thus, different junction states and environmental conditions enable unique sets of emergent mechanical and signal integration beyond single cell behavior. Future classification of different types of collective versus single-cell behaviors will depend on careful dissection of each functional module associated in a junction-, cell-type-, and tissue-specific context.

Conceptual frameworks based on classifying types of collective movements and their links to single-cell migration and other types of tissue dynamics, such as tissue folding and convergent extension, will further allow us to integrate molecular signaling concepts, for example, on EMT or stemness, with varying degrees of cell-cell cooperation. Based on their central function in defining the shape, molecular composition, and duration of cell-cell cooperation, multiscale analysis integrating simultaneously engaged junction mechanisms and their signaling cross talk will be required to delineate which individual and cooperative functions guide or compromise collective decision-making and outcome.

\section{ACKNOWLEDGMENTS}

We thank Adam Shellard and András Szabo for comments on the manuscript. Work from the P.F. laboratory is supported by grants from the European Research Council (617430-DEEPINSIGHT), NWO-Vici (918.11.626), Horizon 2020 consortium MULTIMOT (634107-2), the Cancer Genomics Center, and the MD Anderson Cancer Center Moon Shot program, and from R.M. by grants from MRC and BBSRC.

\section{REFERENCES} Abmayr SM, Pavlath GK. 2012. Myoblast fusion: Lessons
from flies and mice. Development 139: 641-656.
Alexander S, Koehl GE, Hirschberg M, Geissler EK, Friedl P.
2008. Dynamic imaging of cancer growth and invasion: A 
P. Friedl and R. Mayor

modified skin-fold chamber model. Histochem Cell Biol 130: $1147-1154$

Arvanitis DN, Behar A, Tryoen-Toth P, Bush JO, Jungas T, Vitale N, Davy A. 2013. Ephrin B1 maintains apical adhesion of neural progenitors. Development 140: 2082 2092.

Bailey CH, Kaang BK, Chen M, Martin KC, Lim CS, Casadio A, Kandel ER. 1997. Mutation in the phosphorylation sites of MAP kinase blocks learning-related internalization of apCAM in Aplysia sensory neurons. Neuron 18: 913-924.

Balda MS, Matter K. 2016. Tight junctions as regulators of tissue remodelling. Curr Opin Cell Biol 42: 94-101.

Barczyk M, Carracedo S, Gullberg D. 2010. Integrins. Cell Tissue Res 339: 269-280.

Baum B, Georgiou M. 2011. Dynamics of adherens junctions in epithelial establishment, maintenance, and remodeling. J Cell Biol 192: 907-917.

Bazellieres E, Conte V, Elosegui-Artola A, Serra-Picamal X, Bintanel-Morcillo M, Roca-Cusachs P, Munoz JJ, SalesPardo M, Guimera R, Trepat X. 2015. Control of cell-cell forces and collective cell dynamics by the intercellular adhesome. Nat Cell Biol 17: 409-420.

Bouvard D, Pouwels J, De Franceschi N, Ivaska J. 2013. Integrin inactivators: Balancing cellular functions in vitro and in vivo. Nat Rev Mol Cell Biol 14: 430-442.

Bronsert P, Enderle-Ammour K, Bader M, Timme S, Kuehs M, Csanadi A, Kayser G, Kohler I, Bausch D, Hoeppner J, et al. 2014. Cancer cell invasion and EMT marker expression: A three-dimensional study of the human cancerhost interface. J Pathol 234: 410-422.

Brugues A, Anon E, Conte V, Veldhuis JH, Gupta M, Colombelli J, Munoz JJ, Brodland GW, Ladoux B, Trepat X. 2014. Forces driving epithelial wound healing. Nat Physics 10: 683-690.

Bryant DM, Roignot J, Datta A, Overeem AW, Kim M, Yu W, Peng X, Eastburn DJ, Ewald AJ, Werb Z, et al. 2014. A molecular switch for the orientation of epithelial cell polarization. Dev Cell 31: 171-187.

Carmona-Fontaine C, Matthews HK, Kuriyama S, Moreno M, Dunn GA, Parsons M, Stern CD, Mayor R. 2008. Contact inhibition of locomotion in vivo controls neural crest directional migration. Nature 456: 957-961.

Cavallaro U, Christofori G. 2004. Cell adhesion and signalling by cadherins and Ig-CAMs in cancer. Nat Rev Cancer 4: $118-132$.

Chapnick DA, Liu X. 2014. Leader cell positioning drives wound-directed collective migration in TGF $\beta$-stimulated epithelial sheets. Mol Biol Cell 25: 1586-1593.

Charrasse S, Comunale F, Grumbach Y, Poulat F, Blangy A, Gauthier-Rouviere C. 2006. RhoA GTPase regulates Mcadherin activity and myoblast fusion. Mol Biol Cell 17: 749-759.

Cheung KJ, Ewald AJ. 2014. Illuminating breast cancer invasion: Diverse roles for cell-cell interactions. Curr Opin Cell Biol 30: 99-111.

Cheung KJ, Ewald AJ. 2016. A collective route to metastasis: Seeding by tumor cell clusters. Science 352: 167-169.

Cheung KJ, Gabrielson E, Werb Z, Ewald AJ. 2013. Collective invasion in breast cancer requires a conserved basal epithelial program. Cell 155: 1639-1651.
Collins C, Nelson WJ. 2015. Running with neighbors: Coordinating cell migration and cell-cell adhesion. Curr Opin Cell Biol 36: 62-70.

Delva E, Kowalczyk AP. 2009. Regulation of cadherin trafficking. Traffic 10: 259-267.

Dravis C, Henkemeyer M. 2011. Ephrin-B reverse signaling controls septation events at the embryonic midline through separate tyrosine phosphorylation-independent signaling avenues. Dev Biol 355: 138-151.

Ebnet K, Suzuki A, Ohno S, Vestweber D. 2004. Junctional adhesion molecules (JAMs): More molecules with dual functions? J Cell Sci 117: 19-29.

Ellison D, Mugler A, Brennan MD, Lee SH, Huebner RJ, Shamir ER, Woo LA, Kim J, Amar P, Nemenman I, et al. 2016. Cell-cell communication enhances the capacity of cell ensembles to sense shallow gradients during morphogenesis. Proc Natl Acad Sci 113: E679-E688.

Fagerholm SC, Hilden TJ, Nurmi SM, Gahmberg CG. 2005. Specific integrin $\alpha$ and $\beta$ chain phosphorylations regulate LFA-1 activation through affinity-dependent and -independent mechanisms. J Cell Biol 171: 705-715.

Farooqui R, Fenteany G. 2005. Multiple rows of cells behind an epithelial wound edge extend cryptic lamellipodia to collectively drive cell-sheet movement. J Cell Sci 118: $51-63$.

Foster KE, Gordon J, Cardenas K, Veiga-Fernandes H, Makinen T, Grigorieva E, Wilkinson DG, Blackburn CC, Richie E, Manley NR, et al. 2010. EphB-ephrin-B2 interactions are required for thymus migration during organogenesis. Proc Natl Acad Sci 107: 13414-13419.

Friedl P, Gilmour D. 2009. Collective cell migration in morphogenesis, regeneration and cancer. Nat Rev Mol Cell Biol 10: 445-457.

Friedl P, Noble PB, Walton PA, Laird DW, Chauvin PJ, Tabah RJ, Black M, Zanker KS. 1995. Migration of coordinated cell clusters in mesenchymal and epithelial cancer explants in vitro. Cancer Res 55: 4557-4560.

Friedl P, Locker J, Sahai E, Segall JE. 2012. Classifying collective cancer cell invasion. Nat Cell Biol 14: 777-783.

Fukuyama T, Ogita H, Kawakatsu T, Inagaki M, Takai Y. 2006. Activation of Rac by cadherin through the c-SrcRap1-phosphatidylinositol 3-kinase-Vav2 pathway. Oncogene 25: 8-19.

Garver TD, Ren Q, Tuvia S, Bennett V. 1997. Tyrosine phosphorylation at a site highly conserved in the L1 family of cell adhesion molecules abolishes ankyrin binding and increases lateral mobility of neurofascin. J Cell Biol 137: 703-714.

Ghysen A, Dambly-Chaudiere C. 2004. Development of the zebrafish lateral line. Curr Opin Neurobiol 14: 67-73.

Gonzalez-Mariscal L, Dominguez-Calderon A, Raya-Sandino A, Ortega-Olvera JM, Vargas-Sierra O, MartinezRevollar G. 2014. Tight junctions and the regulation of gene expression. Semin Cell Dev Biol 36: 213-223.

Gray RS, Cheung KJ, Ewald AJ. 2010. Cellular mechanisms regulating epithelial morphogenesis and cancer invasion. Curr Opin Cell Biol 22: 640-650.

Gunzer M, Weishaupt C, Hillmer A, Basoglu Y, Friedl P, Dittmar KE, Kolanus W, Varga G, Grabbe S. 2004. A spectrum of biophysical interaction modes between $\mathrm{T}$ 
cells and different antigen-presenting cells during prim ing in 3-D collagen and in vivo. Blood 104: 2801-2809.

Haeger A, Krause M, Wolf K, Friedl P. 2014. Cell jamming. Collective invasion of mesenchymal tumor cells imposed by tissue confinement. Biochim Biophys Acta 1840: 23862395.

Haeger A, Wolf K, Zegers MM, Friedl P. 2015. Collective cell migration: Guidance principles and hierarchies. Trends Cell Biol 25: 556-566.

Harris TJ, Tepass U. 2010. Adherens junctions: From molecules to morphogenesis. Nat Rev Mol Cell Biol 11: 502514.

Hava D, Forster U, Matsuda M, Cui S, Link BA, Eichhorst J, Wiesner B, Chitnis A, Abdelilah-Seyfried S. 2009. Apical membrane maturation and cellular rosette formation during morphogenesis of the zebrafish lateral line. $J$ Cell Sci 122: 687-695.

Hegerfeldt Y, Tusch M, Brocker EB, Friedl P. 2002. Collective cell movement in primary melanoma explants: Plasticity of cell-cell interaction, $\beta 1$-integrin function, and migration strategies. Cancer Res 62: 2125-2130.

Herrmann JR, Turner JR. 2016. Beyond Ussing's chambers: Contemporary thoughts on integration of transepithelial transport. Am J Physiol Cell Physiol 310: C423-C431.

Hivert B, Liu Z, Chuang CY, Doherty P, Sundaresan V. 2002. Robol and Robo2 are homophilic binding molecules that promote axonal growth. Mol Cell Neurosci 21: 534-545.

Hordijk PL, ten Klooster JP, van der Kammen RA, Michiels F, Oomen LC, Collard JG. 1997. Inhibition of invasion of epithelial cells by Tiam1-Rac signaling. Science 278: 1464-1466.

Huang B, Jolly MK, Lu M, Tsarfaty I, Ben-Jacob E, Onuchic JN. 2015. Modeling the transitions between collective and solitary migration phenotypes in cancer metastasis. Sci Rep 5: 17379.

Huebner RJ, Neumann NM, Ewald AJ. 2016. Mammary epithelial tubes elongate through MAPK-dependent coordination of cell migration. Development 143: 983-993.

Ilina O, Friedl P. 2009. Mechanisms of collective cell migration at a glance. J Cell Sci 122: 3203-3208.

Ilina O, Bakker GJ, Vasaturo A, Hofmann RM, Friedl P. 2011. Two-photon laser-generated microtracks in 3D collagen lattices: Principles of MMP-dependent and -independent collective cancer cell invasion. Phys Biol 8: 015010.

Ivetic A, Deka J, Ridley A, Ager A. 2002. The cytoplasmic tail of L-selectin interacts with members of the Ezrin-Radixin-Moesin (ERM) family of proteins: Cell activationdependent binding of Moesin but not Ezrin. J Biol Chem 277: 2321-2329.

Jolly MK, Boareto M, Huang B, Jia D, Lu M, Ben-Jacob E, Onuchic JN, Levine H. 2015. Implications of the hybrid epithelial/mesenchymal phenotype in metastasis. Front Oncol 5: 155 .

Juliano RL. 2002. Signal transduction by cell adhesion receptors and the cytoskeleton: Functions of integrins, cadherins, selectins, and immunoglobulin-superfamily members. Annu Rev Pharmacol Toxicol 42: 283-323.

Kahn J, Walcheck B, Migaki GI, Jutila MA, Kishimoto TK. 1998. Calmodulin regulates L-selectin adhesion molecule expression and function through a protease-dependent mechanism. Cell 92: 809-818.
Kalluri R, Weinberg RA. 2009. The basics of epithelial-mesenchymal transition. J Clin Invest 119: 1420-1428.

Kania A, Klein R. 2016. Mechanisms of ephrin-Eph signalling in development, physiology and disease. Nat Rev Mol Cell Biol 17: 240-256.

Keleman K, Ribeiro C, Dickson BJ. 2005. Comm function in commissural axon guidance: Cell-autonomous sorting of Robo in vivo. Nat Neurosci 8: 156-163.

Khalil AA, Friedl P. 2010. Determinants of leader cells in collective cell migration. Integr Biol 2: 568-574.

Kidd T, Bland KS, Goodman CS. 1999. Slit is the midline repellent for the robo receptor in Drosophila. Cell 96: 785-794.

Kotini M, Mayor R. 2015. Connexins in migration during development and cancer. Dev Biol 401: 143-151.

Kovacs EM, Ali RG, McCormack AJ, Yap AS. 2002. E-cadherin homophilic ligation directly signals through Rac and phosphatidylinositol 3-kinase to regulate adhesive contacts. J Biol Chem 277: 6708-6718.

Krusche B, Ottone C, Clements MP, Johnstone ER, Goetsch K, Lieven H, Mota SG, Singh P, Khadayate S, Ashraf A, et al. 2016. EphrinB2 drives perivascular invasion and proliferation of glioblastoma stem-like cells. eLife 5: e14845.

Kuriyama S, Theveneau E, Benedetto A, Parsons M, Tanaka M, Charras G, Kabla A, Mayor R. 2014. In vivo collective cell migration requires an LPAR2-dependent increase in tissue fluidity. J Cell Biol 206: 113-127.

Lammermann T, Afonso PV, Angermann BR, Wang JM, Kastenmuller W, Parent CA, Germain RN. 2013. Neutrophil swarms require LTB4 and integrins at sites of cell death in vivo. Nature 498: 371-375.

Lecaudey V, Cakan-Akdogan G, Norton WH, Gilmour D. 2008. Dynamic Fgf signaling couples morphogenesis and migration in the zebrafish lateral line primordium. Development 135: 2695-2705.

Legg JA, Herbert JM, Clissold P, Bicknell R. 2008. Slits and Roundabouts in cancer, tumour angiogenesis and endothelial cell migration. Angiogenesis 11: 13-21.

Lorraine C, Wright CS, Martin PE. 2015. Connexin43 plays diverse roles in co-ordinating cell migration and wound closure events. Biochem Soc Trans 43: 482-488.

Luissint AC, Nusrat A, Parkos CA. 2014. JAM-related proteins in mucosal homeostasis and inflammation. Semin Immunopathol 36: 211-226.

Malet-Engra G, Yu W, Oldani A, Rey-Barroso J, Gov NS, Scita G, Dupre L. 2015. Collective cell motility promotes chemotactic prowess and resistance to chemorepulsion. Curr Biol 25: 242-250.

Mayor R, Etienne-Manneville S. 2016. The front and rear of collective cell migration. Nat Rev Mol Cell Biol 17: 97109.

Mertens AE, Rygiel TP, Olivo C, van der Kammen R, Collard JG. 2005. The Rac activator Tiam 1 controls tight junction biogenesis in keratinocytes through binding to and activation of the Par polarity complex. J Cell Biol 170: 10291037.

Montell DJ, Yoon WH, Starz-Gaiano M. 2012. Group choreography: Mechanisms orchestrating the collective movement of border cells. Nat Rev Mol Cell Biol 13: 631-645. 
Nanba D, Toki F, Tate S, Imai M, Matsushita N, Shiraishi K, Sayama K, Toki H, Higashiyama S, Barrandon Y. 2015. Cell motion predicts human epidermal stemness. J Cell Biol 209: 305-315.

Nguyen-Ngoc KV, Ewald AJ. 2013. Mammary ductal elongation and myoepithelial migration are regulated by the composition of the extracellular matrix. J Microsc 251: 212-223.

Nguyen-Ngoc KV, Cheung KJ, Brenot A, Shamir ER, Gray RS, Hines WC, Yaswen P, Werb Z, Ewald AJ. 2012. ECM microenvironment regulates collective migration and local dissemination in normal and malignant mammary epithelium. Proc Natl Acad Sci 109: E2595-E2604.

Nieto MA, Huang RY, Jackson RA, Thiery JP. 2016. Emt: 2016. Cell 166: 21-45.

Niewiadomska P, Godt D, Tepass U. 1999. DE-Cadherin is required for intercellular motility during Drosophila oogenesis. J Cell Biol 144: 533-547.

Oda Y, Otani T, Ikenouchi J, Furuse M. 2014. Tricellulin regulates junctional tension of epithelial cells at tricellular contacts through Cdc42. J Cell Sci 127: 4201-4212.

Osswald M, Jung E, Sahm F, Solecki G, Venkataramani V, Blaes J, Weil S, Horstmann H, Wiestler B, Syed M, et al. 2015. Brain tumour cells interconnect to a functional and resistant network. Nature 528: 93-98.

Otani T, Ichii T, Aono S, Takeichi M. 2006. Cdc42 GEF Tuba regulates the junctional configuration of simple epithelial cells. J Cell Biol 175: 135-146.

Ozawa M. 2015. E-cadherin cytoplasmic domain inhibits cell surface localization of endogenous cadherins and fusion of C2C12 myoblasts. Biol Open 4: 1427-1435.

Park JA, Atia L, Mitchel JA, Fredberg JJ, Butler JP. 2016. Collective migration and cell jamming in asthma, cancer and development. J Cell Sci 129: 3375-3383.

Parvani JG, Galliher-Beckley AJ, Schiemann BJ, Schiemann WP. 2013. Targeted inactivation of $\beta 1$ integrin induces $\beta 3$ integrin switching, which drives breast cancer metastasis by TGF- $\beta$. Mol Biol Cell 24: 3449-3459.

Peifer M. 1993. The product of the Drosophila segment polarity gene armadillo is part of a multi-protein complex resembling the vertebrate adherens junction. J Cell Sci 105: $993-1000$.

Plutoni C, Bazellieres E, Le Borgne-Rochet M, Comunale F, Brugues A, Seveno M, Planchon D, Thuault S, Morin N, Bodin S, et al. 2016. P-cadherin promotes collective cell migration via a Cdc42-mediated increase in mechanical forces. J Cell Biol 212: 199-217.

Porterfield WB, Prescher JA. 2015. Tools for visualizing cell-cell "interactomes." Curr Opin Chem Biol 24: 121130.

Reffay M, Parrini MC, Cochet-Escartin O, Ladoux B, Buguin A, Coscoy S, Amblard F, Camonis J, Silberzan P. 2014. Interplay of RhoA and mechanical forces in collective cell migration driven by leader cells. Nat Cell Biol 16: 217-223.

Revenu C, Streichan S, Dona E, Lecaudey V, Hufnagel L, Gilmour D. 2014. Quantitative cell polarity imaging defines leader-to-follower transitions during collective migration and the key role of microtubule-dependent adherens junction formation. Development 141: 1282 1291.
Riggins KS, Mernaugh G, Su Y, Quaranta V, Koshikawa N, Seiki M, Pozzi A, Zent R. 2010. MT1-MMP-mediated basement membrane remodeling modulates renal development. Exp Cell Res 316: 2993-3005.

Ritsma L, Ellenbroek SI, Zomer A, Snippert HJ, de Sauvage FJ, Simons BD, Clevers H, van Rheenen J. 2014. Intestinal crypt homeostasis revealed at single-stem-cell level by in vivo live imaging. Nature 507: 362-365.

Sarkar S, Bi D, Zhang J, Ren J, Behringer RP, Chakraborty B. 2016. Shear-induced rigidity of frictional particles: Analysis of emergent order in stress space. Phys Rev E 93: 042901.

Sarpal R, Pellikka M, Patel RR, Hui FY, Godt D, Tepass U. 2012. Mutational analysis supports a core role for Drosophila $\alpha$-catenin in adherens junction function. J Cell Sci 125: 233-245.

Sauka-Spengler T, Bronner-Fraser M. 2008. A gene regulatory network orchestrates neural crest formation. Nat Rev Mol Cell Biol 9: 557-568.

Scarpa E, Szabo A, Bibonne A, Theveneau E, Parsons M, Mayor R. 2015. Cadherin switch during EMT in neural crest cells leads to contact inhibition of locomotion via repolarization of forces. Dev Cell 34: 421-434.

Schill NJ, Anderson RA. 2009. Out, in and back again: PtdIns $(4,5) \mathrm{P}(2)$ regulates cadherin trafficking in epithelial morphogenesis. Biochem J 418: 247-260.

Scott RW, Hooper S, Crighton D, Li A, Konig I, Munro J, Trivier E, Wickman G, Morin P, Croft DR, et al. 2010 LIM kinases are required for invasive path generation by tumor and tumor-associated stromal cells. J Cell Biol 191: 169-185.

Senger DR, Davis GE. 2011. Angiogenesis. Cold Spring Harb Perspect Biol 3: a005090.

Shamir ER, Ewald AJ. 2015. Adhesion in mammary development: Novel roles for E-cadherin in individual and collective cell migration. Curr Topics Dev Biol 112: 353-382.

Shapiro L, Weis WI. 2009. Structure and biochemistry of cadherins and catenins. Cold Spring Harb Perspect Biol 1: a003053.

Shiau CE, Bronner-Fraser M. 2009. N-cadherin acts in concert with Slit1-Robo2 signaling in regulating aggregation of placode-derived cranial sensory neurons. Development 136: $4155-4164$.

Sunyer R, Conte V, Escribano J, Elosegui-Artola A, Labernadie A, Valon L, Navajas D, Garcia-Aznar JM, Munoz JJ, Roca-Cusachs P, et al. 2016. Collective cell durotaxis emerges from long-range intercellular force transmission. Science 353: 1157-1161.

Tada M, Heisenberg CP. 2012. Convergent extension: Using collective cell migration and cell intercalation to shape embryos. Development 139: 3897-3904.

Takai Y, Miyoshi J, Ikeda W, Ogita H. 2008. Nectins and nectin-like molecules: Roles in contact inhibition of cell movement and proliferation. Nat Rev Mol Cell Biol 9: 603-615.

Takeichi M. 2014. Dynamic contacts: Rearranging adherens junctions to drive epithelial remodelling. Nat Rev Mol Cell Biol 15: 397-410. 
Te Boekhorst V, Friedl P. 2016. Plasticity of cancer cell invasion-Mechanisms and implications for therapy. $A d v$ Cancer Res 132: 209-264.

Te Boekhorst V, Preziosi L, Friedl P. 2016. Plasticity of cell migration in vivo and in silico. Annu Rev Cell Dev Biol 32: 491-526.

Teddy JM, Kulesa PM. 2004. In vivo evidence for short- and long-range cell communication in cranial neural crest cells. Development 131: 6141-6151.

Terry SJ, Zihni C, Elbediwy A, Vitiello E, Leefa Chong San IV, Balda MS, Matter K. 2011. Spatially restricted activation of RhoA signalling at epithelial junctions by p114RhoGEF drives junction formation and morphogenesis. Nat Cell Biol 13: 159-166.

Theveneau E, Mayor R. 2011. Can mesenchymal cells undergo collective cell migration? The case of the neural crest. Cell Adh Migr 5: 490-498.

Theveneau E, Mayor R. 2012a. Cadherins in collective cell migration of mesenchymal cells. Curr Opin Cell Biol 24: 677-684.

Theveneau E, Mayor R. 2012b. Neural crest delamination and migration: From epithelium-to-mesenchyme transition to collective cell migration. Dev Biol 366: 34-54.

Theveneau E, Mayor R. 2012c. Neural crest migration: Interplay between chemorepellents, chemoattractants, contact inhibition, epithelial-mesenchymal transition, and collective cell migration. Wiley Interdiscip Rev Dev Biol 1: $435-445$.

Theveneau E, Mayor R. 2013. Collective cell migration of epithelial and mesenchymal cells. Cell Mol Life Sci 70: 3481-3492.

Theveneau E, Marchant L, Kuriyama S, Gull M, Moepps B, Parsons M, Mayor R. 2010. Collective chemotaxis requires contact-dependent cell polarity. Dev Cell 19: 3953.

Thiery JP, Acloque H, Huang RY, Nieto MA. 2009. Epithelial-mesenchymal transitions in development and disease. Cell 139: 871-890.

Truong HH, Xiong J, Ghotra VP, Nirmala E, Haazen L, Le Devedec SE, Balcioglu HE, He S, Snaar-Jagalska BE, Vreugdenhil E, et al. 2014. $\beta 1$ integrin inhibition elicits a prometastatic switch through the TGF $\beta$-miR-200-ZEB network in E-cadherin-positive triple-negative breast cancer. Sci Signal 7: ra15.

Van Itallie CM, Anderson JM. 2014. Architecture of tight junctions and principles of molecular composition. Semin Cell Dev Biol 36: 157-165.

Venhuizen JH, Zegers MM. 2016. Making heads or tails of it Cell-cell adhesion in cellular and supracellular polarity in collective migration. Cold Spring Harb Perspect Biol doi: 10.1101/cshperspect.a027854

Waite JC, Leiner I, Lauer P, Rae CS, Barbet G, Zheng H, Portnoy DA, Pamer EG, Dustin ML. 2011. Dynamic im- aging of the effector immune response to listeria infection in vivo. PLoS Pathog 7: e1001326.

Wei CJ, Xu X, Lo CW. 2004. Connexins and cell signaling in development and disease. Annu Rev Cell Dev Biol 20: 811-838.

Weigelin B, Bakker GJ, Friedl P. 2012. Intravital third harmonic generation microscopy of collective melanoma cell invasion: Principles of interface guidance and microvesicle dynamics. Intravital 1: 32-43.

Willecke K, Eiberger J, Degen J, Eckardt D, Romualdi A, Guldenagel M, Deutsch U, Sohl G. 2002. Structural and functional diversity of connexin genes in the mouse and human genome. Biol Chem 383: 725-737.

Wolf K, Wu YI, Liu Y, Geiger J, Tam E, Overall C, Stack MS, Friedl P. 2007. Multi-step pericellular proteolysis controls the transition from individual to collective cancer cell invasion. Nat Cell Biol 9: 893-904.

Wong MH, Rubinfeld B, Gordon JI. 1998. Effects of forced expression of an $\mathrm{NH} 2$-terminal truncated $\beta$-Catenin on mouse intestinal epithelial homeostasis. J Cell Biol 141: $765-777$.

Xu X, Li WE, Huang GY, Meyer R, Chen T, Luo Y, Thomas MP, Radice GL, Lo CW. 2001. Modulation of mouse neural crest cell motility by $\mathrm{N}$-cadherin and connexin 43 gap junctions. J Cell Biol 154: 217-230.

Yamaguchi N, Mizutani T, Kawabata K, Haga H. 2015. Leader cells regulate collective cell migration via Rac activation in the downstream signaling of integrin $\beta 1$ and PI3K. Sci Rep 5: 7656.

Ypsilanti AR, Zagar Y, Chedotal A. 2010. Moving away from the midline: New developments for Slit and Robo. Development 137: 1939-1952.

Zegers MM, Friedl P. 2014. Rho GTPases in collective cell migration. Small GTPases 5: e28997.

Zegers MM, Forget MA, Chernoff J, Mostov KE, ter Beest MB, Hansen SH. 2003. Pak1 and PIX regulate contact inhibition during epithelial wound healing. $E M B O J$ 22: $4155-4165$.

Zhang A, Hitomi M, Bar-Shain N, Dalimov Z, Ellis L, Velpula KK, Fraizer GC, Gourdie RG, Lathia JD. 2015. Connexin 43 expression is associated with increased malignancy in prostate cancer cell lines and functions to promote migration. Oncotarget 6: 11640-11651.

Zihni C, Mills C, Matter K, Balda MS. 2016. Tight junctions: From simple barriers to multifunctional molecular gates. Nat Rev Mol Cell Biol 17: 564-580.

Zucchini C, Manara MC, Pinca RS, De Sanctis P, Guerzoni C, Sciandra M, Lollini PL, Cenacchi G, Picci P, Valvassori L, et al. 2014. CD99 suppresses osteosarcoma cell migration through inhibition of ROCK2 activity. Oncogene 33: 1912-1921. 


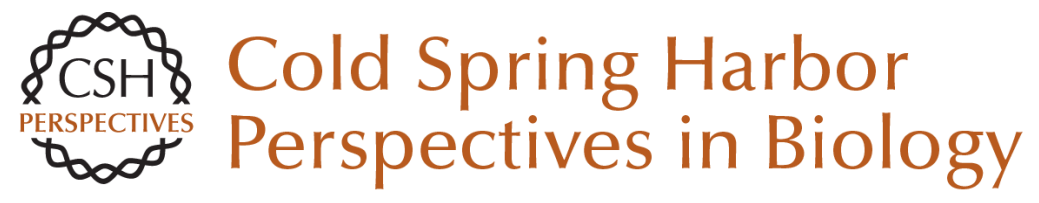

\section{Tuning Collective Cell Migration by Cell-Cell Junction Regulation}

Peter Friedl and Roberto Mayor

Cold Spring Harb Perspect Biol 2017; doi: 10.1101/cshperspect.a029199 originally published online January 17, 2017

\section{Subject Collection Cell-Cell Junctions}

Vascular Endothelial (VE)-Cadherin, Endothelial Adherens Junctions, and Vascular Disease Maria Grazia Lampugnani, Elisabetta Dejana and Costanza Giampietro

Adherens Junctions and Desmosomes Coordinate Mechanics and Signaling to Orchestrate Tissue Morphogenesis and Function: An Evolutionary Perspective Matthias Rübsam, Joshua A. Broussard, Sara A. Wickström, et al.

Cell-Cell Contact and Receptor Tyrosine Kinase Signaling Christine Chiasson-MacKenzie and Andrea I. McClatchey

Hold Me, but Not Too Tight--Endothelial Cell-Cell Junctions in Angiogenesis Anna Szymborska and Holger Gerhardt

\section{Connexins and Disease}

Mario Delmar, Dale W. Laird, Christian C. Naus, et al.

Cell Junctions in Hippo Signaling

Ruchan Karaman and Georg Halder

Loss of E-Cadherin-Dependent Cell-Cell Adhesion and the Development and Progression of Cancer Heather C. Bruner and Patrick W.B. Derksen
Signaling by Small GTPases at Cell-Cell Junctions: Protein Interactions Building Control and Networks Vania Braga

Making Connections: Guidance Cues and Receptors at Nonneural Cell-Cell Junctions Ian V. Beamish, Lindsay Hinck and Timothy E. Kennedy

The Cadherin Superfamily in Neural Circuit Assembly James $D$. Jontes

Mechanosensing and Mechanotransduction at Cell-Cell Junctions Alpha S. Yap, Kinga Duszyc and Virgile Viasnoff

Beyond Cell-Cell Adhesion: Sensational

Cadherins for Hearing and Balance Avinash Jaiganesh, Yoshie Narui, Raul Araya-Secchi, et al.

Cell-Cell Junctions Organize Structural and Signaling Networks Miguel A. Garcia, W. James Nelson and Natalie Chavez

Cell Biology of Tight Junction Barrier Regulation and Mucosal Disease Aaron Buckley and Jerrold R. Turner

For additional articles in this collection, see http://cshperspectives.cshlp.org/cgi/collection/

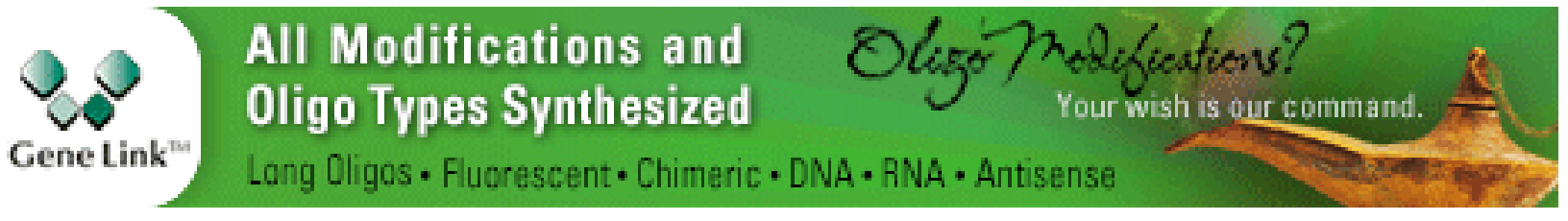


Desmosomes and Intermediate Filaments: Their Consequences for Tissue Mechanics Mechthild Hatzfeld, René Keil and Thomas M. Magin
Integration of Cadherin Adhesion and

Cytoskeleton at Adherens Junctions

René Marc Mège and Noboru Ishiyama

For additional articles in this collection, see http://cshperspectives.cshlp.org/cgi/collection/

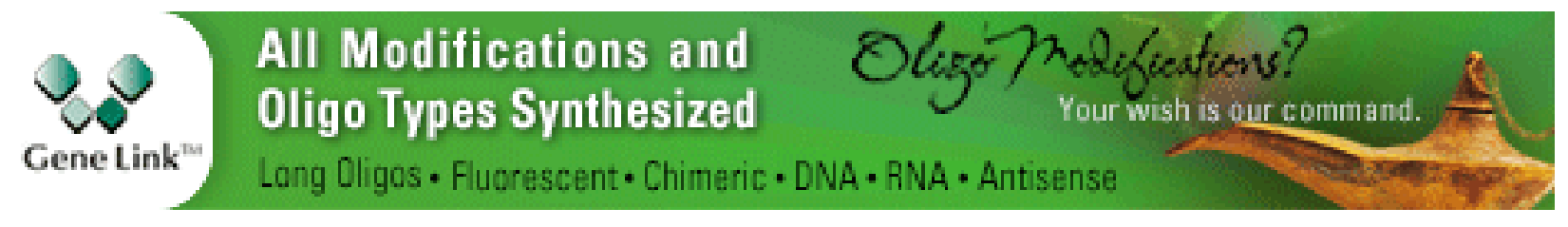

Copyright @ 2017 Cold Spring Harbor Laboratory Press; all rights reserved 